\title{
CI NQR Spectra of Some New Iridium Chlorochalcogenide Complexes
}

\author{
Z. A. Fokina*, V. I. Pekhnyo, S. V. Volkov, and V. F. Lapko \\ Institute of General and Inorganic Chemistry, 32-34 Pr. Palladina, \\ Kiev-142, 252680, Ukraine
}

Y. V. Bryukhova and S. I. Kuznetsov

Institute of Organoelement Compounds. 28 Vavilova St, Moscow, Russia

Z. Naturforsch. 48b, 986-990 (1993); received July 14, 1992

Iridium(III,IV), Chlorochalcogenide Complexes, Synthesis, NQR Spectra

The ${ }^{35} \mathrm{Cl} \mathrm{NQR}$ spectra of the chlorochalcogenide complexes of iridium $\left(\mathrm{SCl}_{3}\right)_{2}\left[\mathrm{IrCl}_{6}\right] \mathbf{1}$, $\left(\mathrm{TeCl}_{3}\right)_{2}\left[\mathrm{IrCl}_{6}\right] \mathbf{2},\left(\mathrm{SeCl}_{3}\right)\left[\mathrm{IrCl}_{6}\right] \mathbf{3},\left[\mathrm{IrCl}_{3}\left(\mathrm{SCl}_{2}\right)_{2}\right]_{2} \mathbf{4},\left(\mathrm{SCl}_{3}\right)\left[\mathrm{IrCl}_{4}\left(\mathrm{SCl}_{2}\right)_{2}\right] \mathbf{5}$ and $\left[\mathrm{IrCl}_{3}\left(\mathrm{SeCl}_{2}\right)_{2}\right]_{2} \mathbf{6}$ have been studied. The spectra were recorded by pulse spectrometry. They consist of two mul tiplets, widely separated in frequency. The high-frequency multiplet belongs to the chlorine atoms bonded to sulfur, selenium and tellurium, respectively, in the ligand. A high-frequency shift is observed, which is typical for the coordination of the molecules $\mathrm{ACl}_{2}(\mathrm{~A}=\mathrm{S}, \mathrm{Se})$ and $\mathrm{ACl}_{4}(\mathrm{~A}=\mathrm{S}, \mathrm{Se}, \mathrm{Te})$. The low frequencies in the multiplets of $\mathbf{4}$ and $\mathbf{6}$ are attributed to additional bonds formed between chalcogen atom and chlorine in the coordination environment of iridium.

In the spectral region $18-24 \mathrm{MHz}$ lie the NQR frequencies of ${ }^{35} \mathrm{Cl}$ bonded to iridium. For 2 the frequencies are close to those of $\left[\mathrm{IrCl}_{6}\right]^{2-}$, which confirms the Ir oxidation state IV. The unexpectedly high frequencies for $\operatorname{Ir}^{\mathrm{III}}$ in the case of $\mathbf{4}$ and $\mathbf{5}$ are explained by the influence of $\mathrm{ACl}_{2}$ molecules, which are weaker $\sigma$-donors than the chloro ligands. This promotes electron density transfer from neighbouring chlorine atoms. The $18 \mathrm{MHz}$ frequency is assigned to the bridge chlorine atoms in dimeric molecule 4 . This assignment is confirmed by the positive value of $\mathrm{d} v / \mathrm{dT}=+0,2$.

\section{Introduction}

The ${ }^{35} \mathrm{Cl}$ NQR spectra for iridium complexes are known only for the coordination anions $\left[\mathrm{Ir}^{\mathrm{III}} \mathrm{Cl}_{6}\right]^{3-}$ and $\left[\mathrm{Ir}^{\mathrm{IV}} \mathrm{Cl}_{6}\right]^{2-}$, where iridium has the electronic configurations $t_{2 g}^{5}$ and $t_{2 g}^{6}$, respectively [1]. Unlike platinum and palladium chloro complexes, in which a strong increase of the ${ }^{35} \mathrm{Cl}$ NQR frequency from 18 to $26 \mathrm{MHz}$ is observed when increasing the oxidation state from II to IV, this change is very small for the above iridium complexes, namely $18 \mathrm{MHz}$ for $\operatorname{Ir}(\mathrm{III})$ and $20 \mathrm{MHz}$ for $\operatorname{Ir}(\mathrm{IV})$. The authors account this for the $\mathrm{p}_{\mathrm{Cl}}-\mathrm{d}_{\mathrm{Ir}}$ interaction involving chlorine $\mathrm{p} \pi$-electrons and unoccupied d-orbitals of iridium(IV), which has one vacancy in the $t_{2 g}^{5}$ electronic configuration.

In the present paper ${ }^{35} \mathrm{Cl}$ NQR spectra of chlorochalcogenide complexes of iridium are given. The analysis of these spectra and the comparison with the spectra of $\left[\mathrm{Ir}^{\mathrm{III}} \mathrm{Cl}_{6}\right]^{3-}$ and $\left[\mathrm{Ir}^{\mathrm{IV}} \mathrm{Cl}_{6}\right]^{2-}$ complexes made it possible to confirm the oxidation

\footnotetext{
* Reprint requests to Prof. Z. A. Fokina.

Verlag der Zeitschrift für Naturforschung, D-72072 Tübingen

0932-0776/93/0700-0986/\$01.00/0
}

state of iridium, the structure of these compounds and the influence of ligands in the coordination sphere.

\section{Synthesis and Characterization of the Complexes}

We have synthesized and studied iridium chlorocomplexes with the chalcogen chlorides $\mathrm{ACl}_{2}$ (where $\mathrm{A}=\mathrm{S}, \mathrm{Se}$ ) and $\mathrm{ACl}_{4}$ (where $\mathrm{A}=\mathrm{S}, \mathrm{Se}, \mathrm{Te}$ ) of the following compositions: $\left(\mathrm{SCl}_{3}\right)_{2}\left[\mathrm{IrCl}_{6}\right] \mathbf{1}$, $\left(\mathrm{TeCl}_{3}\right)_{2}\left[\mathrm{IrCl}_{6}\right] \mathbf{2},\left(\mathrm{SeCl}_{3}\right)_{2}\left[\mathrm{IrCl}_{6}\right] \mathbf{3},\left[\mathrm{IrCl}_{3}\left(\mathrm{SCl}_{2}\right)_{2}\right]_{2} \mathbf{4}$, $\left(\mathrm{SCl}_{3}\right)\left[\mathrm{IrCl}_{4}\left(\mathrm{SCl}_{2}\right)_{2}\right] \mathbf{5},\left[\mathrm{IrCl}_{3}\left(\mathrm{SeCl}_{2}\right)_{2}\right]_{2} \mathbf{6}$.

The structure of these new compounds has been studied by spectroscopic methods (IR, Raman, diffusive reflection spectroscopy), their magnetic properties have been investigated [2], and an X-ray structure analysis has been carried out for complex 5 [3]. Difficulties in the synthesis of chlorochalcogenide complexes iridium made it impossible to obtain sufficient amounts of each compound which were necessary for ${ }^{35} \mathrm{Cl}$ NQR spectra measurements. Whereas the synthesis of chalcogen chloride complexes of other platinum metals $(\mathrm{Pt}$, $\mathrm{Pd}, \mathrm{Os}, \mathrm{Rh}, \mathrm{Ru}$ ) proceeds within several hours and involves the formation of one molecular species, 
the preparation of iridium complexes takes longer time and in some cases leads to the formation of a mixture of complexes. For example, when a selenium complex was synthesized, unreacted starting selenium tretrachloride was detected in the reaction mixture after $20 \mathrm{~h}$ heating (Fig. 1) and the transformation was complete after about $100 \mathrm{~h}$.

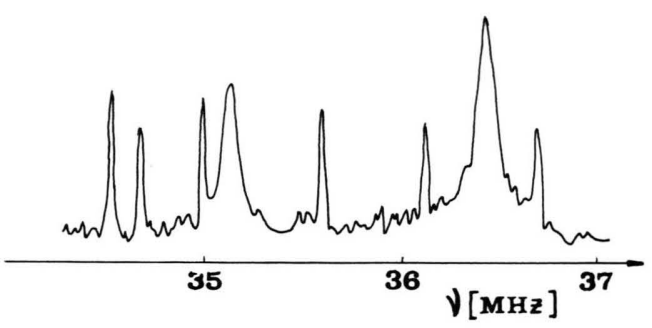

Fig. 1. The ${ }^{35} \mathrm{Cl} \mathrm{NQR}$ spectrum of reaction mixture after $20 \mathrm{~h}$ heating $\left(\mathrm{SCl}_{3}\right)_{2}\left[\mathrm{IrCl}_{6}\right]$ complex with $\mathrm{SeCl}_{4}$.

Since all the iridium complexes $\mathbf{1 - 6}$ are air-moisture sensitive, they were preparated and purified in sealed ampules or closed vessels in order to avoid hydrolysis. The starting compound for producing all chalcogen chloride complexes of iridium was $\mathrm{IrCl}_{4} \cdot n \mathrm{H}_{2} \mathrm{O}$. By synthesis in the presence of chlorine gas, the oxidation state $\operatorname{Ir}(\mathrm{IV})$ remains in $\mathbf{1 , 2}$ and $\mathbf{3}$, while in $\mathbf{4 , 5}$ and $\mathbf{6}$ the reduction $\operatorname{Ir}(\mathrm{IV})$ $\mathrm{Ir}(\mathrm{III})$ takes place in the solvents $\mathrm{SCl}_{2}$ and $\mathrm{SeCl}_{2}$.

Complex 1 was produced by heating a solution of $\mathrm{IrCl}_{4} \cdot n \mathrm{H}_{2} \mathrm{O}$ in $\mathrm{SCl}_{2}$ for $20 \mathrm{~h}$ in a chlorine stream containing wine-red crystals.

$$
\begin{aligned}
& \text { Analysis for }\left(\mathrm{SCl}_{3}\right)_{2}\left[\mathrm{IrCl}_{6}\right] \\
& \text { Calcd Ir } 28.17 \mathrm{~S} 9.40 \mathrm{Cl} 62.43 \% \text {, } \\
& \text { Found Ir } 28.10 \quad \mathrm{~S} 9.20 \mathrm{Cl} 61.30 \% \text {. }
\end{aligned}
$$

Since the crystals of this complex possess piezoelectric properties, we could not obtain any ${ }^{35} \mathrm{Cl}$ NQR spectrum.

Complex 2 was produced by heating 1 with a stoichiometric amount of $\mathrm{TeCl}_{4}$ in thionyl chloride under passing of chlorine for $20 \mathrm{~h}$ by the reaction: $\left(\mathrm{SCl}_{3}\right)_{2}\left[\mathrm{IrCl}_{6}\right]+2 \mathrm{TeCl}_{4}=\left(\mathrm{TeCl}_{3}\right)_{2}\left[\mathrm{IrCl}_{6}\right]+2 \mathrm{SCl}_{2}+$ $2 \mathrm{Cl}_{2}$ containing precipitated black crystals and gave a well resolved ${ }^{35} \mathrm{Cl} \mathrm{NQR}$ spectrum.

$$
\begin{aligned}
& \text { Analysis for }\left(\mathrm{TeCl}_{3}\right)_{2}\left[\mathrm{IrCl}_{6}\right] \\
& \text { Calcd Ir 22.01 Te 29.10 Cl 47.80\%, } \\
& \text { Found Ir } 22.00 \text { Te } 29.10 \quad \mathrm{Cl} 47.80 \% \text {. }
\end{aligned}
$$

Complex 3 was produced by heating 1 with a stoichiometric amount of $\mathrm{SeCl}_{4}$ in thionyl chloride under passing of chlorine for $100 \mathrm{~h}$ containing precipitated black crystals.

$$
\begin{aligned}
& \text { Analysis for }\left(\mathrm{SeCl}_{3}\right)_{2}\left[\mathrm{IrCl}_{6}\right] \\
& \text { Calcd Ir } 24.79 \text { Se } 20.33 \mathrm{Cl} 54.88 \% \text {, } \\
& \text { Found Ir } 24.70 \text { Se } 20.20 \quad \text { Cl 54.20\%. }
\end{aligned}
$$

The corresponding ${ }^{35} \mathrm{Cl}$ NQR spectrum was obtained.

To produce 4, a weighted amount of $\mathrm{IrCl}_{4} \cdot n \mathrm{H}_{2} \mathrm{O}$ was heated with a twenty-fold excess of sulfur dichloride until $\mathrm{SO}_{2}$ evolution ceased and a yellow precipitate formed by the reaction

$$
\begin{aligned}
& 2\left(\mathrm{IrCl}_{4} \cdot n \mathrm{H}_{2} \mathrm{O}\right)+5 \mathrm{SCl}_{2}= \\
& {\left[\mathrm{IrCl}_{3}\left(\mathrm{SCl}_{2}\right)_{2}\right]_{2}+\mathrm{SO}_{2}+4 \mathrm{HCl} .}
\end{aligned}
$$

The ampule was sealed, the solution was transferred to the other end of the ampule. After sealing-off, the crystal were dried under vacuum.

$$
\begin{aligned}
& \text { Analysis for }\left[\mathrm{IrCl}_{3}\left(\mathrm{SCl}_{2}\right)_{2}\right]_{2} \\
& \text { Calcd Ir 38.12 S } 12.67 \mathrm{Cl} 49.21 \% \text {, } \\
& \text { Found } \mathrm{Ir} 38.10 \mathrm{~S} 12.70 \mathrm{Cl} 49.10 \% \text {. }
\end{aligned}
$$

The ${ }^{35} \mathrm{Cl}$ NQR spectrum of this sample exhibited a broad line at $40 \mathrm{MHz}$. We succeeded in obtaining a well-resolved spectrum only after a repeated recrystallization of $\mathbf{4}$ in sulfur dichloride. It turned out, however, that a chemical transformation takes place by the reaction:

$$
\left[\mathrm{IrCl}_{3}\left(\mathrm{SCl}_{2}\right)_{2}\right]_{2}+4 \mathrm{SCl}_{2} \rightleftarrows 2\left(\mathrm{SCl}_{3}\right)\left[\mathrm{IrCl}_{4}\left(\mathrm{SCl}_{2}\right)_{2}\right]
$$

leading to the equilibrium existence of two complex species, namely $451 \%$ and $\mathbf{5} 49 \%$ *.

From the mixture the crystals of 5 have been selected and the X-ray structure analysis has been carried out [3]. A further heating and recrystallization did not affect the composition. Thus, the ${ }^{35} \mathrm{Cl}$ NQR spectrum corresponded with the mixture of crystals of 4 and 5 (Fig. 2).

To produce 6 , a weighted amount of $\mathrm{IrCl}_{4} \cdot n \mathrm{H}_{2} \mathrm{O}$ was heated with selenium tetrachloride in a $1: 2$ ratio in a solution of thionyl chloride until $\mathrm{SO}_{2}$ evolution ceased. Then it was heated in a sealed ampule for 20-30 h until the black precipitate changed completely to orange crystals of 6 .

\footnotetext{
* The content of two complex species in the mixture was calculated from the results of a chemical analysis (Ir 32.5; S 13.1; $\mathrm{Cl}$ 52.0) using the standard Gauss method for a set of three equations in two unknowns.
} 
Analysis for $\left[\mathrm{IrCl}_{3}\left(\mathrm{SeCl}_{2}\right)_{2}\right]_{2}$

Calcd Ir 32.15 Se $26.35 \mathrm{Cl} 41.50 \%$,

Found Ir 32.00 Se $26.20 \quad \mathrm{Cl} 41.20 \%$.

The ${ }^{35} \mathrm{Cl}$ NQR spectrum of 6 obtained is shown in Fig. 2.
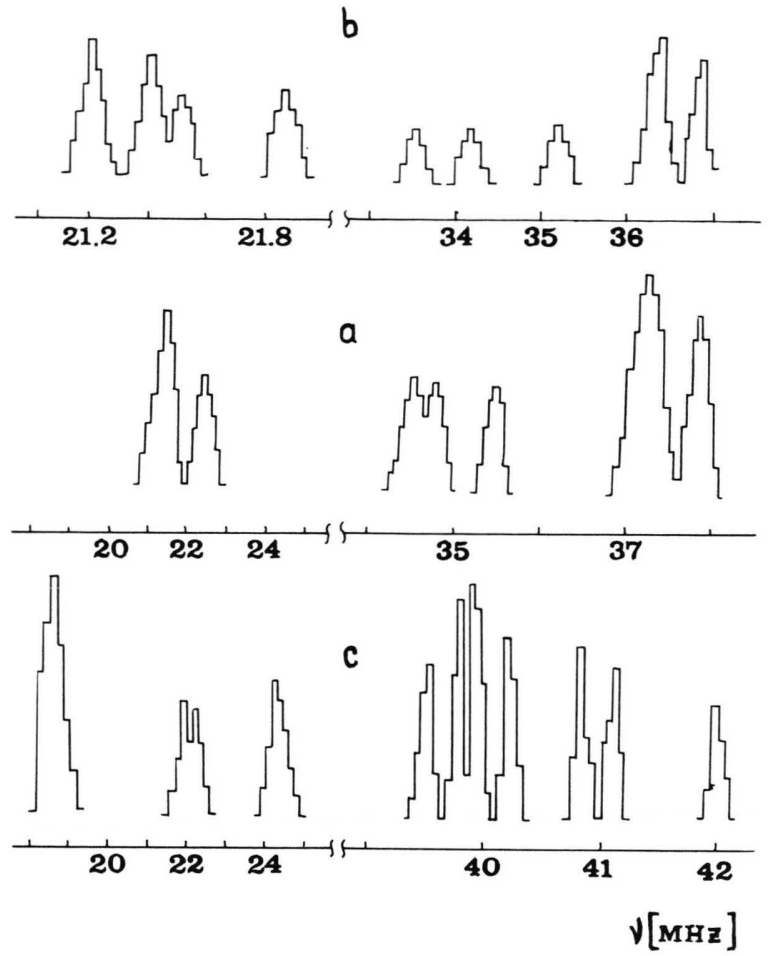

Fig. 2. The ${ }^{35} \mathrm{Cl} \mathrm{NQR}$ spectra of iridium chlorochalcogenide complexes:

a) Complex $\left[\mathrm{IrCl}_{3}\left(\mathrm{SeCl}_{2}\right)_{2}\right]_{2}$ at $77 \mathrm{~K}$.

b) Complex $\left[\mathrm{IrCl}_{3}\left(\mathrm{SeCl}_{2}\right)_{2}\right]_{2}$ at $296 \mathrm{~K}$.

c) Mixture of two complex species: $\left[\mathrm{IrCl}_{3}\left(\mathrm{SCl}_{2}\right)_{2}\right]_{2}+$ $\left(\mathrm{SCl}_{3}\right)\left[\mathrm{IrCl}_{4}\left(\mathrm{SCl}_{2}\right)_{2}\right]$ at $77 \mathrm{~K}$.

\section{Discussion of the ${ }^{35} \mathrm{Cl}$ NQR Spectra, Results}

a) Complex 1-2

The ${ }^{35} \mathrm{Cl}$ NQR spectrum of complex 2 consists of two multiplets that are widely separated in frequency (Table I). The high-frequency multiplet lies somewhat higher than for pure tellurium tetrachloride but in the same frequency range as for platinum, gold and osmium complexes $[4,5]$. This indicates the presence of the $\mathrm{TeCl}_{3}$ grouping. A small high-frequency shift may be due to charge transfer by complex formation. The low-frequency multiplet was assigned to chlorine bonded to iridium, the different ranges make such an assignment unambiguous. The frequency values are close to the spectrum of the $\left[\mathrm{Ir}^{\mathrm{IV}} \mathrm{Cl}_{6}^{2-}\right]$ anion and confirm the presence of iridium(IV). The small multiplet separation is rather caused by the asymmetrical placing of molecules in the crystal. The nature of both the high-frequency and low-frequency multiplets indicates most probably the presence of two crystallographically non-equivalent complex molecules in the crystal.

\section{b) Complex 3}

In the ${ }^{35} \mathrm{Cl} \mathrm{NQR}$ spectrum of $\mathbf{3}$, we were able to obtain only the high-frequency region, which was assigned to the resonance of chlorine atoms bonded to selenium. The frequency values fall within the range of spectra of pure $\mathrm{SeCl}_{4}$. The line intensity ratio in the doublet is $1: 2$, which seems to be due to the complex molecule being symmetrically disposed in the crystal along the twofold axis.

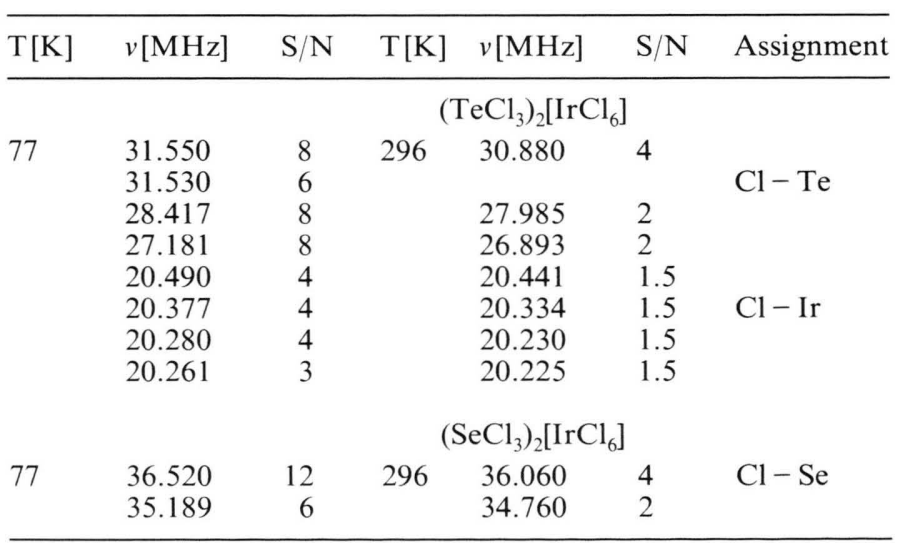

Table I. ${ }^{35} \mathrm{Cl} \mathrm{NQR}$ frequencies for iridium complexes. 


\section{c) Complex 4-5}

The spectrum of the mixture of $\mathbf{4}$ and $\mathbf{5}$ exhibits a complicated multiplet in the high-frequency region and a distant triplet of wide separation (Table II). Such a frequency distribution in the spectrum allows an unambiguous assignment of the high-frequency multiplet to chlorine, bonded to sulfur atoms and of the triplet to chlorine, bonded to an iridium atom. We were able to analyze the complicated multiplet after considering the intensities of the frequencies of 15 chlorine atoms bonded to sulfur (Fig. 2). The frequencies 42.015 and $41.125 \mathrm{MHz}$ are appreciably higher in comparison with those of a free $\mathrm{SCl}_{2}$ molecule [6]. This occurs due to charge transfer by complex formation and is typical for chlorochalcogenide complexes of platinum, palladium and gold [7]. They contain the $\mathrm{SCl}_{2}$ molecule or $\mathrm{SCl}_{3}$ groups as a component. By analogy with these complexes, the doublet $42.015,41.123 \mathrm{MHz}$ with a double-intensity line could be assigned to be $\mathrm{SCl}_{3}$ groups in $\mathbf{5}$.

The presence of resonance lines with a low frequency $(39.045$ and $39.542 \mathrm{MHz})$ in the multiplet may be attributed to the formation of additional bonds formed between sulfur and chlorine atoms which are in the coordination environment of iridium. A similar frequency decrease in the ligand was observed in molybdenum and tungsten com- plexes $\left[\mathrm{MS}_{2} \mathrm{Cl}_{3}\left(\mathrm{SeCl}_{2}\right)\right]_{2}$ [8]; in which seleniumchlorine contacts were revealed by $\mathrm{X}$-ray structure analysis [9]. Similar extended bonds were detected in a rhodium complex $\left[\mathrm{RhCl}_{3}\left(\mathrm{SeCl}_{2}\right)_{2}\right]_{2}$ [3]. This additional bonding must lead to a charge increase at the sulfur atom and hence to a decrease of the ${ }^{35} \mathrm{Cl} \mathrm{NQR}$ frequency in the $\mathrm{SCl}_{2}$ ligand. If this assumption is true, the low frequencies in the multiplet can be assigned to 4 .

The triplet separation reaches $30 \%$, which indicates chemical non-equivalence of the chlorine atoms at iridium. When assigning ${ }^{35} \mathrm{Cl} \mathrm{NQR}$ frequencies in this region, the peculiarities of the electronic structure of iridium(III) were taken into account. It has the electronic $\mathrm{t}_{2 \mathrm{~g}}^{6}$ configuration with two electron vacancies on the high-lying $e_{g}$ orbitals, which are not involved in the $\mathrm{p}_{\mathrm{Cl}}-\mathrm{d}_{\mathrm{Ir}} \pi$-type of interaction. The substitution of a neutral chalcogen dichloride molecule for the chloro ligand in such complexes enhances the electron density transfer from the chlorine atoms bonded to the metal and hence increases the ${ }^{35} \mathrm{Cl} \mathrm{NQR} \mathrm{frequency}$ of these atoms. In $\mathrm{Pt}(\mathrm{IV})$ complexes $\mathrm{PtCl}_{4}\left(\mathrm{SCl}_{2}\right)_{2}$ and $\mathrm{PtCl}_{4}\left(\mathrm{SeCl}_{2}\right)_{2}$ this increase reaches $10 \%$. Thus, the appearance of an unexpectedly high frequency $(24.542 \mathrm{MHz})$ in $\mathbf{4}$ and $\mathbf{5}$, which is unusual to iridium(III) complexes, may be due to the intraspheric influence of the $\mathrm{SCl}_{2}$ ligand, which possesses weak $\sigma$-donor properties. The secondary-bonding effect,

\begin{tabular}{|c|c|c|c|c|c|c|}
\hline $\mathrm{T}[\mathrm{K}]$ & $v[\mathrm{MHz}]$ & $\mathrm{S} / \mathrm{N}$ & $\mathrm{T}[\mathrm{K}]$ & $v[\mathrm{MHz}]$ & $\mathrm{S} / \mathrm{N}$ & Assignment \\
\hline & & \multicolumn{5}{|c|}{$\left[\mathrm{IrCl}_{3}\left(\mathrm{SCl}_{2}\right)_{2}\right]_{2}+\left(\mathrm{SCl}_{3}\right)\left[\mathrm{IrCl}_{4}\left(\mathrm{SCl}_{2}\right)_{2}\right]$} \\
\hline \multirow[t]{9}{*}{77} & 42.015 & 6 & 296 & 40.420 & 3 & \\
\hline & 41.125 & 8 & & 40.070 & 5 & \\
\hline & 40.835 & 10 & & 39.382 & 5 & $\mathrm{Cl}-\mathrm{S}$ \\
\hline & 40.205 & 10 & & 39.080 & 5 & \\
\hline & 39.945 & 20 & & 38.985 & 6 & \\
\hline & 39.593 & 10 & & 38.763 & 4 & \\
\hline & 24.542 & 15 & & 24.246 & 1.5 & \\
\hline & 22.054 & 15 & & 21.840 & 1.5 & $\mathrm{Cl}-\mathrm{Ir}$ \\
\hline & 18.720 & 30 & & 18.758 & 3 & \\
\hline \multicolumn{7}{|c|}{$\left[\mathrm{IrCl}_{3}\left(\mathrm{SeCl}_{2}\right)_{2}\right]_{2}$} \\
\hline \multirow[t]{9}{*}{77} & 37.698 & 10 & 296 & 36.894 & 2 & \\
\hline & 37.300 & 15 & & 36.437 & 3 & \\
\hline & 35.463 & 5 & & 35.175 & 1 & \\
\hline & 34.603 & 5 & & 34.170 & 1 & $\mathrm{Cl}-\mathrm{Se}$ \\
\hline & 34.560 & 5 & & 33.888 & 1 & \\
\hline & 22.053 & 10 & & 21.896 & 1 & \\
\hline & & & & 21.440 & 1 & \\
\hline & & & & 21.400 & 2 & $\mathrm{Cl}-\mathrm{Ir}$ \\
\hline & 21.469 & 20 & & 21.181 & 2 & \\
\hline
\end{tabular}

Table II. ${ }^{35} \mathrm{Cl} \mathrm{NQR}$ frequencies for iridium complexes. 
which was pointed out previously [8], must lead to some decrease in the frequency $(22.054 \mathrm{MHz})$ of chlorine bonded to iridium owing to the formation of weak $\mathrm{Ir}-\mathrm{Cl}-\mathrm{S}$ bridge bonds. At last the 18.720 $\mathrm{MHz}$ frequency relates most probably to the bridging chlorine atoms in dimeric $\mathbf{4}$. The positive temperature coefficient value $\mathrm{d} v / \mathrm{dT}=+0.2$ confirms assignment.

\section{d) Complex 6}

The ${ }^{35} \mathrm{Cl}$ NQR spectrum of complex 6 consists of a complicated high-frequency multiplet and a distant doublet with a double-intensity line, which were assigned to chlorine bonded to selenium and iridium, respectively (Table II). It was found that the character of the multiplet, considering the line intensity, corresponds to eight chlorine atoms bonded to selenium. The frequencies 37.648 and $37.300 \mathrm{MHz}$ are close in value to the spectra of the complexes $\mathrm{PtCl}_{4}\left(\mathrm{SeCl}_{2}\right)_{2}$ and $\mathrm{PdCl}_{2}\left(\mathrm{SeCl}_{2}\right)_{2}$ [4], and the low-lying frequencies 34.560 and $34.603 \mathrm{MHz}$ are close to the spectra of the complexes $\left[\mathrm{MoS}_{2} \mathrm{Cl}_{3}\left(\mathrm{SeCl}_{2}\right)_{2}\right]_{2}$ and $\left[\mathrm{WS}_{2} \mathrm{Cl}_{3}\left(\mathrm{SeCl}_{2}\right)_{2}\right]_{2}$. The latter compounds exhibit secondary bonding, which seems also occur in complex 6.

The NQR frequencies of ${ }^{35} \mathrm{Cl}$ bonded to iridium are much higher compared to the spectra of $\mathrm{M}_{3}\left[\mathrm{IrCl}_{6}\right]$ complexes; this is caused by the influence of coordinated $\mathrm{SeCl}_{2}$ molecules, which are weak $\sigma$-donors. Secondary bonding to the selenium atom in the $\mathrm{SeCl}_{2}$ ligand and the formation of bridging chlorines bonding two iridium atoms must decrease the NQR frequencies of ${ }^{35} \mathrm{Cl}$ at iridium. Comparison of the spectra of 4,5 and 6 makes it possible to assign the $24.642 \mathrm{MHz}$ frequency to chlorine atom in $\mathbf{5}$. However, a more detailed assignment of ${ }^{35} \mathrm{Cl} \mathrm{NQR}$ frequencies in this region appears to be impossible before the Zeeman split NQR measurements are accomplished.
[1] K. Ito, D. Nakamura, K. Ito, and M. Kubo, Inorg. Chem. 2, 690 (1963); P. J. Crosswell, J. E. Fergusson, and B. R. Penfold, JCSD 3, 254 (1972).

[2] V. I. Pekhnyo, S. V. Volkov, Z. A. Fokina, and N. I. Timoshchenko, Ukr. Khim. Zhurn. 47, No. 9, 1215 (1981).

[3] V. B. Ribakov, L. A. Aslanov, S. V. Volkov, V. I. Pekhnyo, A. V. Grafov, and Z. A. Fokina, Zhurn. Strukt. Khim. 33, 3, 146 (1992).

[4] Z. A. Fokina, S. I. Kuznetsov, Y. V. Bryukhova, and N. I. Timoshchenko, Koord. Khimia 6, No. 9, 1463 (1980).

[5] Z. A. Fokina, Y. V. Bryukhova, V. I. Pekhnyo, and
S. I. Kuznetsov, Izv. AN SSSR, Ser. Khim. 6, 1409 (1986).

[6] T. A. Babushkina, V. S. Levin, M. I. Kalinkin, and G. K. Semin, Izv. AN SSSR, Ser. Khim. 10, 2340 (1969).

[7] Z. A. Fokina, S. I. Kuznetsov, Y. V. Bryukhova, and N. I. Timoshchenko, Koord. Khimiya 3, No. 8, 1235 (1977).

[8] Z. A. Fokina, S. I. Kuznetsov, N. I. Timoshchenko, V. L. Kolesnichenko, Y. V. Bryukhova, and G. K. Semin, Izv. AN SSSR, Ser. Khim. 4, 902 (1984).

[9] S. V. Volkov, V. L. Kolesnichenko, and N. I. Timoshchenko, I. Coord. Chem. 17, 367 (1988). 